Article

\title{
Digital Media Platforms and the Use of TV Content: Binge Watching and Video-on-Demand in Germany
}

\author{
Lothar Mikos \\ Department of Media Studies, Filmuniversity Babelsberg Konrad Wolf, 14482 Potsdam, Germany; \\ E-Mail: I.mikos@filmuniversitaet.de
}

Submitted: 24 December 2015 | Accepted: 8 March 2016 | Published: 14 July 2016

\begin{abstract}
The advancing digitalization and media convergence demands TV broadcasting companies to adjust their content to various platforms and distribution channels. The internet, as convergent carrier medium, is increasingly taking on a central role for additional media. Classical linear TV is still important, but for some audiences it has been developing from a primary medium to a secondary medium. Owing to the growing melding of classical-linear TV contents with online offerings (e.g. video-on-demand platforms or Web-TV), a great dynamic can be seen which has triggered numerous discussions about the future of TV for some time now. This article will summarize the results of two different audience studies. Film and television shows are meanwhile distributed online via Video-on-Demand platforms such as Netflix or Amazon Prime Video. The first audience study has dealt with the use of VoD-platforms in Germany investigating user rituals, user motivation to watch films and TV shows on these platforms, and the meaning of VoD in everyday life. Most of the participants in this study reported that they mainly watch TV drama series at Netflix or Amazon Prime. Therefore, the second audience study focused the online use of television drama series of individuals and couples elaborating the phenomenon of binge watching. In relating the audience practice to the new structures of the television market the article will shed light on the future of television.
\end{abstract}

\section{Keywords}

audiences; binge watching; convergence; digitalization; television, television culture; television series; video-on-demand

\section{Issue}

This article is part of the issue "(Not Yet) the End of Television", edited by Milly Buonanno (University of Roma "La Sapienza", Italy).

(C) 2016 by the author; licensee Cogitatio (Lisbon, Portugal). This article is licensed under a Creative Commons Attribution 4.0 International License (CC BY).

\section{Introduction}

Recently there has been a spate of declarations that the end of television, usually with the qualifier "as we know it", is imminent. The medium is perceived as an obsolete model whose future is anything but certain. At the same time, however, the number of television channels has grown considerably in most Western countries, including Denmark, Germany, Italy, Sweden, the United Kingdom and the US. We are said to be living in the "multichannel age" (D'Arma, 2010). There is more and more television, and television is still a contemporary technology and form of culture (Lotz, 2007; Williams, 1974). In the autumn of 2009, Henry Jenkins posed the critical question in a blog: "In a social networking world, what's the future of TV?" (Jenkins, 2009). The same year, Elihu Katz (2009) gave a very general answer to the question "The End of Television?" by pointing out that television had been undergoing institutional change from its beginnings, and moreover, the values and the everyday lives of its audience had also changed. Television has always been a medium in transition, subject to constant transformation. Beginning in the mid-1990s, digitalization led to a transformation of television's technology, distribution, economics, media policy and use. "Digitalization allowed interoperability between television and other technologies that came to define the contemporary 
media world. Convergence between television and computers was a key outcome of interoperability" (Lotzl, 2009, p. 53). The phenomenon of convergence has been described variously (cf. Bruhn Jensen, 2010; Dwyer, 2010; Jenkins, 2006; Keane, 2007; Murdock, 2000). As Fagerjord and Storsul (2007) have found, the term convergence is used as a "rhetorical tool" to describe significant changes in the media environment that were set in motion by digitalization. They write: "The current media developments are diverse. What we see are several parallel developments resulting in a higher level of complexity, with new alignments of networks, terminals, services and markets" (Fagerjord \& Storsul, 2007, p. 27). Convergence is used as a simple metaphor to refer to these complex changes. We can surmise, however, that we in the 21st century are living in convergent media environments in which the conventional media (film, television, print) are fusing with the telecommunications and IT industry, both in their technology, economics and aesthetics and at the user level. In view of these developments, Tay and Turner (2010, p. 44) found, "The special question for television studies in the digital era is whether the advent of digital technology has categorically changed the social practice of watching television." For television in the "post-network era" (Lotz, 2007) is diversifying. Television content is no longer receivable only linearly by means of the conventional television set, but can now be used on different platforms and technical devices. The present article collates the findings of two empirical studies dealing with this changed use of television. One of the studies examined the use of video-ondemand in general in Germany; the other focused specifically on the phenomenon of "binge watching" of television series. The findings will be integrated in general tendencies of the development of digital television, and will show that television is a central element of the future of digital media.

\section{Video-on-Demand in Germany}

The market for video-on-demand (VoD) in Germany is growing at an increasing rate. The results of the 2015 ARD/ZDF online study show a clear trend in the younger target group. Among all Internet users, 65\% of Germans of all ages watched moving pictures over the Internet at least occasionally in 2015 (Kupferschmitt, 2015 , p. 383 ), and $20 \%$ watched moving images online every day. But among 14 to 29-year-old Germans who are online, $98 \%$ watch moving pictures on the Internet at least occasionally (ibid., p. 385). Twenty-eight per cent of the young target group do so using videostreaming services such as Netflix and Amazon Prime. Access to VoD among online users overall, whether in the form of subscriptions (S-VoD) or individual transactions (T-VoD), is around a low four percent, however (Zubayr \& Gerhard, 2015, p. 110). Thus the digital use of moving images still makes up a small portion of the time devoted to media use. The trend towards videoon-demand use is expected to grow, however, and mainly among the young target group.

The study described here, conducted in 2014 by Babelsberg Film University, presents a user-oriented survey of the VoD providers available in Germany and their use (Nooke, Jørgensen, \& Mikos, 2015). In the analysis, which is mentioned here only briefly, the offerings considered are those Electronic Sell-Through (EST), S-VoD and T-VoD providers in the German-speaking countries which are independent of broadcasters' linear programming and act as paid, curated portals for the distribution of professionally produced content. These criteria exclude TV networks' media libraries and portals with user-generated content such as YouTube, for example. (If such portals are included, according to a study of video portals in Europe by the European Commission [quoted in Puffer, 2015, p. 24], there are a total of 171 video portals in Germany.) Under the restrictive definition, there are $22 \mathrm{VoD}$ providers, of which ten were selected as relevant in the market and representative of the various niches for a more detailed examination of their content portfolios and user-friendliness.

The analysis shows that the German VoD market is highly diverse and fragmented due to a variety of business models. For example, there are providers which have specialized in the S-VoD delivery model (Netflix, Watchever); others which support only one-time access by pay-per-view or digital purchase (iTunes, Sony Entertainment Network); and others still which combine all three business models (maxdome, Amazon Prime Instant Video). Nonetheless, the providers can be classified, in an analogy with the conventional linear TV environment, as ten full-content portals and twelve special-interest portals. The latter are characterized by a clear thematic focus in their content, with offerings limited to between 100 and 1,500 titles. This is an advantage in terms of user-friendliness, since viewers can orient themselves more easily in the simpler portal structure, and do not have to explore the portal by trial and error. The full-content providers offer more comprehensive, but often more confusing portfolios of up to 60,000 titles. They include mainly mainstream content and popular international productions.

In addition to the analysis of the content offerings, the researchers conducted seven group discussions with a total of 21 men and eleven women aged from 23 to 62 years. The study also incorporated four individual interviews, two with persons less than 18 years old and two with persons over 50 years old. The participants were recruited online and via word of mouth in Berlin and Potsdam. They have to fulfil the criteria of having used a VoD platform and they should belong to different age groups. The objective was to discover patterns of VoD use. The key findings of the study are summarized below. 
The five big full-content providers are both the best-known portals among the respondents to the reception study and those they used most. For that reason, the following presentation of VoD use in Germany refers primarily to Amazon Prime Instant Video, iTunes, maxdome, Netflix and Watchever. The most important motivating factors for the use of VoD portals are scheduling freedom and freedom of movement and equipment. The respondents access VoD portals when they want to consume content relevant to them personally, and they appreciate the freedom to watch a new episode of their favorite series whenever they want, whether or not they are at home. A 44-year-old man explained it in the following terms: "The critical factor is of course to watch it at a time when I need it, when I can make my own schedule...and am not dependent on a program magazine or a program sequence....To me that's the big advantage of VoD". American series such as Breaking Bad, Mad Men and House of Cards were the proximate motivation for many users to subscribe to a VoD portal. In the long term, however, users must be satisfied with the film offerings as well as series in order to stay with a portal. Users see the absence of commercial interruptions as a clear advantage of VoD portals. Several of the respondents also valued the option of watching films and series in the original language with subtitles. Because the users still prefer a large picture and good audio and video quality, most of them use devices such as television sets or laptops for VoD. Mobile devices such as tablets and smartphones play only a marginal role in VoD use.

S-VoD portals are used differently from T-VoD portals. S-VoD portals, which permit users to watch unlimited content for a monthly fee, invite both daily use and phases of intense consumption such as binge watching. The use of T-VoD portals is more selective, since users must pay a fee for each film or series episode they watch. The VoD users surveyed described a number of different search behaviors. There are people who search for specific content, who almost always have a certain film or series title in mind when they access a VoD portal, and people who like to browse through and get ideas from the available content. Many of the respondents use the VoD portals' genre and recommendation rubrics as a sorting function. They repeatedly criticized the genre categories and the platforms' recommendation algorithms, however.

In general, users felt that the term video-ondemand or VoD was unclear. Confusion is caused by the fact that the various platforms offer T-VoD or SVoD or a combination of the two. One 26-year-old woman, for example, said, "I have a problem distinguishing between all these video platforms: is it VoD; is it simply a film platform? What's the business model behind it?" The constantly changing market is also a source of confusion. Furthermore, users differed widely in their evaluation of the platforms' prices and value for money. Up-to-date content and the scope of the offerings were very important criteria. Pure S-VoD offerings are seen as more affordably priced. Many S-VoD portals present little current content, however, which the respondents see as a disadvantage. Many users saw T-VoD as too expensive, but as more up-to-date and offering the widest selection of content. Many of the respondents viewed a mixture of S-VoD and T-VoD as confusing and a disadvantage.

Furthermore, it would appear that VoD is not necessarily a threat to cinema and television, since the respondents evaluated it as no substitute for cinema. Cinema still offers many advantages in their view, including the big screen, very good sound and picture quality, the latest content, and technical refinements such as 3D images and Dolby sound. The respondents also view cinema as a social event. VoD is rather a supplement in several respects to linear television consumption. Yet television still offers formats that are rarely found, if at all, in VoD offerings. All kinds of shows and live broadcasts of sports and other events worldwide are watched on conventional television.

In spite of the perceived advantages of VoD, including independent scheduling and selection of content and the variety of devices on which it can be consumed, the respondents also expressed criticism and suggested improvements. Problems they mentioned often concerned the delivery infrastructure and the speed of data transfer. In all of the group discussions, VoD users complained mainly about the sometimes poor data communications performance, which causes jerky video, brief interruptions and degraded video resolution. Especially during the evenings and on Sundays when traffic is heavy, the network is often overloaded. In regard to the future of VoD in Germany, one of the respondents, a 62-year-old man, said, "I believe that how all this develops will depend heavily on the development of a good, stable Internet. That is a very important criterion." The respondents likewise complained that several portals advertise the availability of original versions and subtitles, but only provide them for individual films or series. Yet the surveyed viewers' main complaint about video-on-demand was that most portals only offer a thematically limited selection of content. They frequently mentioned their wish for a general platform offering highly up-to-date and comprehensive content for a uniform price. Many users referred to the music streaming provider Spotify as a model. According to the respondents, Spotify offers not only the desired comprehensive selection, but also solves the second major problem that still exists with VoD offerings due to licensing conflicts: the long delay before new content is available, since it must first be commercialized in other media or other countries. Film content is available immediately only on illegal platforms. Most of the respondents are well aware that this is due to the license holders' conditions, and that 
the commercialization system would have to be changed overall to compete with the pirate sites.

Video-on-demand makes up only a small proportion of media use overall, but the duration of VoD consumption is steadily growing, especially in the young target group. The five major video portals, Amazon Prime Instant Video, iTunes, maxdome, Netflix and Watchever, are not only those with the largest selection of films and television series in the market, catering primarily to the main stream, but are also the bestknown among the users. The general public so far has little knowledge of the smaller video portals, which primarily serve special interests such as children's films, animé or art-house films. Viewers find the market confusing. Those who are looking for certain films or series have to consult several providers to find what they want. Furthermore, most of the content offered is available only for a limited time due to the licenses that the video portals obtain from the distributors. Hence it is not surprising that the viewers surveyed wanted a single, general platform where they can find everything. Poor Internet access is also an obstacle to the expansion of the video-on-demand market in some places. No one wants to watch films with jerking motion or unintelligible sound.

Nonetheless, VoD portals offer several advantages for viewers. For a relatively affordable subscription price, users of the big portals have access to a huge selection of content. Viewers appreciate being able to watch their films and series without regard to a programming schedule (as in linear television), and can choose the content themselves. These results of the present study corroborate those of other investigations: "scheduling flexibility and independence are identified as the most important motives for VoD consumption" (Puffer, 2015, p. 26). At the same time, the respondents appreciated the advantages of technical availability: most VoD portals can be used not only with a stationary or laptop computer, but also with hybrid or smart TVs, game consoles, smart phones and tablets. Mobile access to the content is perceived as a great advantage.

Video-on-demand does not compete with conventional television, but supplements it. The platforms allow users to watch films and television series, which are otherwise available only on broadcast television or on DVD or Blu-ray, without regard to programs and schedules. In the medium term, the classic home entertainment market will be conquered mainly by $\mathrm{S}$ VoD, supplanting physical media such as DVD and Bluray. In Scandinavia and other European countries where S-VoD portals such as Netflix are well represented, sales of physical media have declined drastically, by almost $40 \%$ in Norway, almost $20 \%$ in Denmark, France and Great Britain, and almost ten percent in Switzerland; only in Germany the market for physical media grew in 2013 by almost 5\% (Keen, 2014). While the market share of portals financed by advertising and TVoD portals is slowly declining, the future appears to be in the S-VoD sector: video portals which offer subscribers a broad selection are increasingly conquering the market. To date, however, the business is not yet profitable in Germany. In the long run, only large portals such as Netflix or Amazon Prime Instant Video will prevail, since they can afford to operate for a number of years before breaking even. The portal Watchever, owned by Universal, got to the break even at the end of 2015 , after two years in which they had to face losses of up to 30 million Euro per quarter.

\section{Binge Watching of Television Series Online}

The term "binge watching" is a metaphor to describe an intensive form of consumption of television series. There is no precise definition. Charlotte Brunsdon (2010, p. 65) calls it "domestic viewing of multiple episodes sequentially." In general we can say that binge watching occurs when a viewer watches two or more episodes of a series in one session. Binge watching is a form of "media marathoning", which places emotional and cognitive demands on the viewers (Perks, 2015), and has its roots in home entertainment via VCR and DVD. The VoD industry has used the term "binge watching" as a marketing tool, exploiting this form of series reception as a unique selling point (Jenner, 2015; Tryon, 2015). DVD boxes of TV series had the same potential, allowing a distinction from mainstream audiences in the consumption of cult films and series (Hills, 2007). Complex narrative structures (Mittell, 2015) reinforce the distinction, since viewers can immerse themselves more deeply in the fictional worlds and so experience the "complex pleasures of narrative, in which one is caught in the contradictory desire to find out what happens next and for the story not to end" (Brunsdon, 2010, p. 66). Moreover, DVDs and VoD platforms allow the viewer to enjoy the narrative without being interrupted by advertising (Jacobs, 2011). Binge watching of television series can be seen as a form of television consumption which only became possible with certain technological and commercial developments in the media market, and at the same time was promoted by certain aesthetic and narrative developments in the television series market.

The study on binge watching at Babelsberg Film University was aimed at discerning patterns of this form of reception (Kranz, 2015a; Kranz, 2015b). The methodology involved group discussions with a total of 16 participants aged from 20 to 61 years. The participants were recruited online and via word of mouth in Berlin, Brandenburg and Saxonia. A condition for participation was that the respondents regularly watch, but not necessarily binge-watch, television series. The key findings of the study are summarized below.

All the respondents were found to have indulged in 
intensive consumption of series at least once. Some of the series viewers had watched whole seasons of series in the space of a few weeks or even days. The series watched in this way ranged from comedies such as How I Met Your Mother to dramas such as Desperate Housewives, Game of Thrones and House of Cards. The respondents confirmed that the complex narratives of the television series are conducive to binge watching: "That is, it really is the fascination of the story being told.... What's being told and most of all how it's told" (28-year-old woman). Viewers continue watching a series because they become accustomed to it, and because they identify more strongly with the characters than with those of a film, a 33-year-old woman remarks. A 53-year-old woman adds, "And of course the series are so attractive, Game of Thrones for example just as much as Arne Dahl, or Borgen, because of the stories they tell." The development of the characters is an important part of the narrative: "Yes, the character development is shown in so much more detail. I mean, it's like a good film, but one that runs 12 hours, or even 40 hours. The Sopranos is a very good example of a good dramatic series in which the characters develop from the beginning over six seasons in which everything kind of fits together. That was in Breaking Bad too; I thought that was quite good too, the way it...yeah, actually there is only one way it can end. That...Walter sooner or later dies, of whatever cause, cancer or drugs. And still you want to know how it happens," said a 33-year-old man. The same respondent added that the complex narrative forms and the development of the heroes of the series make watching more intensive: "I mean, the whole feeling that you build up over such a long time, and so much suspense is sustained for you, that you are completely 'invested'. Emotionally, in the good and the bad things, so that if your favorite character dies, which was the case with Game of Thrones for example." Intensive watching of complex television series requires a high degree of emotional and cognitive participation on the part of the viewers. The public discussion of the new, complex television series, which are considered "quality TV", is one reason for intensive series consumption: "Because these new, good series, people talk about them a lot, and you have an exchange about them with people, that's another reason I feel like watching them. I want to watch The Wire too sometime because people always mention it. So I just want to see it. I'm actually interested in exploring this genre of the new quality series and kind of catching up" (32-year-old woman).

But the viewers try to integrate intensive series watching in their everyday lives. Most of them find the time to watch on weekends. During the week, other activities take priority. A 28-year-old woman reflects on the fact that her professional life leaves her less time to watch series: "Well, in any case I had a lot of time to see a great number of series, and films too. And that happened, on a very large scale. That is, that I really consumed a great deal in a very short time, both on television and on the Internet...and now, as a working person so to speak, tied to getting up early, to a personal life in which I now live together with someone else, where I simply don't have the time for it any more...but sometimes I wish there were no other obligations and I could just watch episodes for four hours at a time. But unfortunately it's out of the question, both for personal and for professional reasons." Binge watching has to be adapted to the viewer's personal circumstances.

Viewers whose professional obligations do not allow intensive watching of series every evening find time primarily on weekends. Binge watching is organized as a kind of personal leisure-time event, sometimes as a social event in a group of friends, or with the viewer's partner, although viewers sometimes binge alone. A 61-year-old man finds he cannot watch together with his wife because theirs is a long-distance relationship. Consequently, when one of the couple discovers a new series, he or she watches it alone and then give the DVD to other: "For example, she watched Boardwalk Empire first and then gave it to me...then she bought the DVD and then I watch it during the week so to speak, or vice versa, because once I lent her The Borgias for example." When they get together on the weekend, they watch "four to five" episodes in a row. In most couples, the partners watch both alone and together. A 25-year-old woman watched True Detective together with her partner, but prefers to watch comedy series such as Modern Family alone: "When I watch alone, it's more a matter of boredom, and I have time on my hands. And when we watch together, it's before bedtime, and then we usually watch just one episode, sometimes two." A problem arises for series fans when one partner is not interested in series, or is interested in different series. Then they plan to watch certain series that are currently the subject of public discussion together. Two of the participating women named series such as Breaking Bad and Game of Thrones as a means of arranging joint watching with their partners. When interests diverge, it is difficult for the respondents to integrate series and binge watching in their relationship. A 28-year-old woman commented, "The question is what he wants to see. And he has Breaking Bad, and all right, then I bow to him so that we can watch a series at all. But he's not at all interested in these series like Revenge and Under the Dome and so on. So I have to watch that when he's doing something else. Then I have time, and then I also watch because I have the time: 'Oh my God, now I can watch five episodes in a row.' And then I watch it. So, partnership, and...we don't live together yet, but something like it, in any case it's another big change." A separation can also change the viewers' use of series. When a partner with whom the viewer used to watch 
series together moves out, there's something missing. A woman and a man, both 33 years old, found their series consumption changed after their separation. While she watches alone still more intensively, he now watches with friends. The examples indicate that series consumption is a social phenomenon. People who watch alone have a need to communicate with friends about the series they have seen. Couples integrate their series consumption in their everyday rituals. Friends plan to watch series as an evening event, mostly on weekends.

Binge watching of television series is a cultural practice that viewers integrate in their everyday lives and adapt to their personal circumstances. The social conditions of their lives limit their consumption of series as both work and partners and children demand a share of their time. When personal circumstances change, series consumption changes too. In addition to DVDs, the new VoD platforms make intensive consumption possible by freeing the content from the fixed programming structure of linear television networks. Complex television series also lend themselves to binge watching since they require more intensive and attentive reception.

\section{Conclusion: Binge Watching, VoD and the Future of Television}

Digitalization has not only changed the marked for audio-visual media, leading to the increasing importance of video portals, but has also changed the audience's behavior. Although conventional television is still dominant, more and more viewers use mobile devices to watch films and television series asynchronously and autonomously. Their changed use habits go hand in hand with new offerings that invite intensive reception. Video-on-demand use and binge watching are examples that illustrate a trend from mass communications to massive personalization (Bolin, 2014). Video-ondemand platforms are the latest form of time-shifting technologies that began with the VCR. The large offer of the platforms allows consumers to individualize their consumption practice. They integrate the new practices in their everyday routines, and sometimes they celebrate the consumption of television series as social event. The freedom of the traditional program schedule of classical linear television is the most important motive for audiences to use VoD platforms. These platforms such as Netflix collect data on their users and use them to produce popular series such as House of Cards, and at the same time to present their users a personalized selection of content. The users in our study repeatedly criticized the platforms recommendation algorithms and they were really unsatisfied with the genre categories that the platform uses to classify their offer.

In the "on-demand culture" (Tryon, 2013), users can consume all kinds of audiovisual content at any time, not only at home, but wherever they go with their mobile devices. Such individualized use is no longer oriented after the conventional, linear programming structures of broadcast television, and leads to a fragmentation of the audience, is connected with the fragmentation of content offerings into increasing numbers of television channels and growing numbers of video portals, such as YouTube, and VoD platforms, such as Netflix and Amazon Prime. Furthermore, more and more conventional television broadcasters and cable networks are going online, offering their content over the Internet, as for example, $\mathrm{HBO}$ is doing with HBO NOW. Other platforms are now looking for the "flow" associated with linear television (Williams, 1974) to hold viewers. Two current trends can be observed: First, VoD platforms put whole seasons of newly produced television series online, encouraging consumers to binge-watch them and so access the platform longer. Second, more and more television series are becoming centers of transmedia extension (Evans, 2011) to encourage consumer loyalty to the series as a single brand on all available platforms. The first trend is a change in production practice, since all episodes of a season have to be finished at once; it is no longer possible to produce the later episodes when the first are already being distributed, as was customary in broadcast television. The aesthetics of the serial narrative are also changing, since the option of watching episodes in rapid succession undermines the effect of cliffhangers and recaps. Yet VoD platforms are a form of television, since all platforms focus their marketing campaigns on the production of new drama and comedy series-the classic forms of television shows, and since most of their customers are looking for television series like the participants in our study. Even if consumers watch films at the platforms they do not evaluate it as a substitute for cinema. For the participants in our study cinema still offer many advantages, including the big screen, fantastic quality of sound and picture, and the latest content. VoD platforms as home entertainment and small screen practice do not compete with the big screen experience of the movie theaters. The cultural practice of cinema going is not substituted by home entertainment. Home technologies such as VCR, DVD, and VoD platforms and their use complement the older practice of cinema going.

The fascination of television stems from the viewer's active participation in the production of meaning; that is what makes the symbolic material of television possible. Yet television continues to develop; it has always been and still is a medium in transition (Spigel, 2004). It is constantly changing. In the digital era, television is able to distribute its content by more paths than before, and can reach the audience in different and better ways. The participants in our study use television content mainly on TV screens and laptops, sel- 
dom on tablets. Meanwhile the genres and formats have not changed very much. The new digital distribution paths are accompanied by a boom in television series and by new forms of marketing of show formats in connection with social media activities. As the results of our study on binge watching have shown, the narrative complexity and the ambiguous characters of Quality TV series drag audiences into the immersive experience of binge watching. Intensive watching of complex television series requires a high degree of emotional and cognitive participation on the part of the audiences. In this respect the results of our study coincide with the study of Perks (2015) in which the author described the affective and cognitive involvement of viewers during media marathoning.

The greatest challenge to the users will be to find their way around in the huge selection of available channels and platforms. For in the digital era, "First, media content and services are proliferating at such a rapid rate that the volume of material is essentially unlimited. Second, media, both old and new, are increasingly available on demand via fully integrated digital networks that allow users to move easily from one thing to the next. Third, the total supply of human attention available to consume those offerings has an upper bound. The widening gap between limitless media and limited attention makes it a challenge for anything to attract an audience" (Webster, 2014, p. 4). As our study shows audiences of VoD platforms are very critically not only about search functions and recommendation algorithms but also about poor data transfer and confusion of the seemingly indefinite offer of the platforms. The participants highlighted the music streaming service Spotify as a model for an excellent online offer. Spotify serves as horizon of expectations for VoD platforms. Users want a convenient service that is easy to handle and has satisfying recommendation algorithms. Consumers need navigational aids to find their shows and to discover new ones. To generate attention among consumers, the operators of platforms and producers of content must increasingly invest in program advertising and marketing, and use channels such as social networks to position themselves in the "marketplace of attention" (Webster, 2014).

The viewers will integrate the brave new television world in their everyday lives just as they did the old. Gauntlett and Hill (1999) have shown how users integrate new technologies into their everyday life. In the chapter "Video and Technology in the Home" they summarize: "More common and domestic concerns about new technologies and services were based around three key concerns - cost, aesthetics and available time..." (Gauntlett \& Hill, 1999, p. 171). This is still true for the respondents in our study. Whereas cost and aesthetic were important concerns about VoD platforms, aesthetic and available time were important concerns about binge watching. As the circumstances of their lives permit, they will develop individual patterns of media use, adapting the use of television content on the various platforms to their equally various life situations. The option of mobile use increases the time spent with television content. Television will not disappear: it will only become available on all existing screens-and so become more present and more important. Nevertheless, it will remain what it always was: a technology and a cultural form (Williams, 1974). The technology has changed, and the cultural practices of consumption have become more diverse, but the consumers are still trying to integrate the use of television series and television shows in their everyday lives and adapt it to their circumstances.

\section{Acknowledgments}

The empirical work would not have been possible without the support of Filmuniversität Babelsberg. The author would like to thank the research group on VOD Sophia Beck, Svenja Böttger, Rahel Fuchs, Kristin Hoffmann, Carolin Höding, Eva K. Klöcker, Antonia Sophie Nooke, Signe S. Jørgensen, Susan Thoma, and Juliane Kranz for the binge watching interviews.

\section{Conflict of Interests}

The author declares no conflict of interests.

\section{References}

Bolin, G. (2014). The death of the mass audience reconsidered. From mass communication to mass personalisation. In S. Eichner \& E. Prommer (Eds.), Fernsehen: Europäische Perspektiven (pp. 159-172). Konstanz: UVK.

Bruhn Jensen, K. (2010). Media Convergence. The three degrees of network, mass, and interpersonal communication. London \& New York: Routledge.

Brunsdon, C. (2010). Bingeing on box-sets: The national and the digital in television crime drama. In J. Gripsrud (Ed.), Relocating television. Television in the digital context (pp. 63-75). London \& New York: Routledge.

D’Arma, A. (2010). Italian television in the multichannel age. Change and continuity in industry structure, programming and consumption. Convergence, 16 (2), 201-215.

Dwyer, T. (2010). Media convergence. Maidenhead \& New York: Open University Press.

Evans, E. (2011). Transmedia television. Audiences, new media and daily life. New York \& London: Routledge.

Fagerjord, A., \& Storsul, T. (2007). Questioning convergence. In T. Storsul \& D. Stuedahl (Eds.), Ambivalence towards convergence. Digitalization and media change (pp. 19-31). Göteborg: Nordicom.

Gauntlett, D., \& Hill, A. (1999). TV living. Television, cul- 
ture and everyday life. London \& New York: Routledge.

Hills, M. (2007). From the box in the corner to the box on the shelf. New Review of Film and Television Studies, 5(1), 41-60.

Jacobs, J. (2011). Television interrupted: Aesthetic or pollution. In J. Bennett \& N. Strange (Eds.), Television as digital media (pp. 255-280). Durham, NC \& London: Duke University Press.

Jenkins, H. (2006). Convergence culture. Where old and new media collide. New York \& London: New York University Press.

Jenkins, H. (2009, September 24). In a social networking world, what's the future of TV? Huffington Post. Retrieved from http://www.huffingtonpost.com/henryjenkins/in-a-social-networking-wo_b_292014.html

Jenner, M. (2015). Binge-watching: Video-on-demand, quality-TV and mainstreaming fandom. International Journal of Cultural Studies. doi: 10.1177/136787791 5606485

Katz, E. (2009). The end of television? The ANNALS of the American Academy of Political and Social Science, 625, 6-18.

Keane, S. (2007). CineTech. Film, convergence and new media. Basingstoke \& New York: Palgrave Macmillan.

Keen, B. (2014, October 6). The future of television in Europe. An assessment of the changing nature of television in Europe, and what is shaping the transformation. Paper presented at the EBU Knowledge Exchange Conference, Stockholm.

Kranz, J. (2015a). Das Phänomen des Binge Watching (Unpublished Master Thesis). Filmuniversität Babelsberg KONRAD WOLF, Germany.

Kranz, J. (2015b). Binge Watching. Die neue Attraktivität von Serien im Internet. TV Diskurs, 19(3), 76-81.

Kupferschmitt, T. (2015). Bewegtbildnutzung nimmt weiter zu-Habitualisierung bei 14-bis 29-Jährigen. Media Perspektiven, 9, 383-391.

Lotz, A. D. (2007). The television will be revolutionized.
New York \& London: New York University Press.

Lotz, A. D. (2009). What is U.S. television now? The ANNALS of the American Academy of Political and Social Science, 625, 49-59.

Mittell, J. (2015). Complex TV. The poetics of contemporary television storytelling. New York \& London: New York University Press.

Murdoch, G. (2000). Digital futures: European television in the age of convergence. In J. Wieten, G. Murdoch, \& P. Dahlgren (Eds.), Television across Europe. A comparative introduction (pp. 35-57). London: Sage.

Nooke, A., Jørgensen, S. S., \& Mikos, L. (2015). Video-ondemand in Deutschland. Angebot und Nutzungsgewohnheiten. TV Diskurs, 19(2), 68-73.

Perks, L. G. (2015). Media marathoning. Immersions in morality. Lanham, MD: Lexington Books.

Puffer, H. (2015). Video-on-demand: Neue Schubkraft durch Netflix? Media Perspektiven, 1, 2015, 17-29.

Spigel, L. (2004). Introduction. In L. Spigel \& J. Olsson (Eds.), Television after TV. Essays on a medium in transition (pp. 1-34). Durham, NC \& London: Duke University Press.

Tay, J., \& Turner, G. (2010). Not the apocalypse: Television futures in the digital age. International Journal of Digital Television, 1(1), 31-50.

Tryon, C. (2013). On-demand culture. Digital delivery and the future of movies. New Brunswick, NJ \& London: Rutgers University Press.

Tryon, C. (2015). TV got better: Netflix's original programming strategies and binge viewing. Media Industry Journal, 2(2), 104-116.

Webster, J. G. (2014). The marketplace of attention. How audiences take shape in a digital age. Cambridge, MA \& London: MIT Press.

Williams, R. (1974). Television. Technology and cultural form. London: Fontana-Collins.

Zubayr, C., \& Gerhard, H. (2015). Tendenzen im Zuschauerverhalten. Media Perspektiven, 3, 110125.

\section{About the Author}

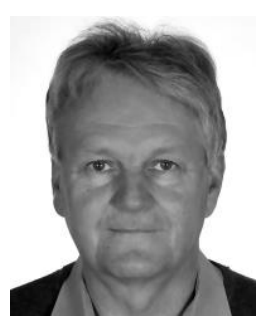

\section{Dr. Lothar Mikos}

Lothar Mikos is Professor of Television Studies in the Department of Media Studies at the Filmuniversität Babelsberg in Potsdam, Germany. He currently serves as chair of the Television Studies Section of the European Communication Research and Education Association (ECREA). He was the managing director of the Erich Pommer Institute for Media Law, Media Economy and Media Research (2010-2014). His main areas of work are Economy of the International TV Format Trade, Television Series Worldwide, Digital Distribution., Convergence Culture, Popular Television Genres and Formats, and Audience Studies. 